\title{
10. Imaginary Screens: The Hypnotic Gesture and Early Film
}

\author{
Ruggero Eugeni
}

\begin{abstract}
Ruggero Eugeni argues that film profited from an insistent reference to hypnosis. If in early depictions, hypnotists were pointing their fingers at the subject in order to hit him or her with a shot of magnetic fluid, by the early twentieth century, subjects were induced into a hypnotic state as the hypnotist's hand waved repeatedly in front of the eyes. This new gestural format, repeatedly staged by the movies of the same period, was instrumental in mirroring and shaping in imaginary terms the film's screening conditions and the viewer's experience. At a moment when a nascent cinema might have been defined in a number of ways, the anachronistic figure of the hypnotist's hand worked to establish the screen rather than the film or the projector as the essential element of an emerging assemblage.
\end{abstract}

Keywords: Silent Film, Dispositif, Vision, Spectatorship

\section{Hypnosis in early cinema: A metaphor of the film-viewing situation}

Between the 1910 and 1920s, the iconography of hypnosis in film was changing. The hypnotist no longer pointed his fingers at the subject, hitting him with a shot of magnetic fluid; instead, subjects now fell into hypnosis as a consequence of the hypnotist waving his hand in slow and repeated gestures in front of their eyes. Occasionally, other hypnotic procedures were also shown, such as the gaze of the hypnotist or the movement of shining objects. But the waving gesture of the hypnotist's hand appears to have held primary interest, for even as it remained marginal in the extra-cinematic practice of hypnosis, it was widely staged and represented in the movies of the period.

Buckley, C., R. Campe, F. Casetti (eds.), Screen Genealogies. From Optical Device to Environmental Medium. Amsterdam: Amsterdam University Press, 2019 DOI 10.5117/9789463729000_CH10 
The predominance of the new hypnotic gesture must be understood in relation to the mutual convergence and progressive overlap between the film-viewing situation experienced by spectators and the hypnotic setup. Such a convergence can be observed from the 1910s, both in film theoretical discourses and in the filmic depictions of hypnosis itself. ${ }^{1}$ In this context, the gesture of the hand passing before the eyes of the hypnotized subject introduces - unlike other inductive gestures, and in particular the blow of energy - an explicit reference to the movie screen as both material and imaginary surface; indeed, its predominance over the 'blow' gesture highlights the key role of the silver screen within the imaginary and metaphorical reorganization of the cinematic situation as a hypnotic scene.

I articulate my discussion in two steps. First, I analyze a number of films produced between 1897 and 1923 that feature hypnosis. I emphasize the metaphorical references to the film-viewing situation and outline the role of the hypnotist's hand, in particular, as a reference to the film screen. I then summarize the development of mesmeric and hypnotic scenarios from their origins at the end of the eighteenth century to the first decade of the twentieth. In doing so, I argue that cinema ends up replacing the hypnotic setup within modernity and that the film screen is a key element in this process. In other words, I analyze the role of the hand-as-screen from both sides of the metaphorical equation: first, the cinema as hypnosis, and then, hypnosis as cinema.

It should be clear that my approach occupies a singular position within the current debate on screen theory. ${ }^{2}$ Indeed, the discussion is often divided between a technological archaeology of the silver screen and its cultural genealogy. On the contrary, I insist on the dynamical and reciprocal interactions between material and imaginary aspects of film screens, and I emphasize how such interactions give birth to that particular cultural and theoretical object that we call the film dispositive.

\section{Shadows, audiences, hallucinations}

In its early period, cinema displayed different representations of hypnosis. At first, when the process of trance induction was staged, the prevailing

1 On the relationship between cinema and hypnosis, especially in reference to early cinema, see Alovisio, 2013; Andriopoulos, 2008; Bellour, 2009; Berton, 2015; Eugeni, 2002, 2003; Gordon, 2001; Killen, 2015; Ronetti, 2018; Schweinitz, 2010; and Väliaho, 2010.

2 See Blassnig, Deutsch, and Schimek, 2013; Chateau and Moure, 2016; Huhtamo, 2004, 2009, 2012; Manovich, 2001; Mitchell, 2015; Musser, 1984, 1990; and William, 2005. 
mise-en-scène involved the 'classic' gesture of the hands pointed towards the body of the hypnotized subject - see, for instance, Chez le magnetiste (Alice Guy Blaché, 1897; Figure 10.1) or L'antre des ésprits (George Méliès, 1901; Figure 10.2). ${ }^{3}$ In doing so, early filmmakers recovered and remediated within the cinematic domain the most widespread and immediately understandable iconography of hypnotic induction of the time: a gesture rooted in the long-established magnetic tradition, linked to the release of fluid energy, and which had already been adopted by contemporary practitioners of hypnosis (see, for instance, Figure 10.3).

Towards the mid-1910s, however, the iconography of hypnosis began to grow in both variety and complexity. A relevant example is Trilby (Maurice Tourneur, 1915), one of the first films to adapt the eponymous best-selling novel by George du Maurier, published in 1894. The plot is centred on a magnetic pair of characters: Svengali, an ambiguous and haunting musicianturned-hypnotist, and Trilby, a humble and compliant girl who, under Svengali's hypnotic spell, turns into a great and famous opera singer.

In the first scene of hypnotic induction, Trilby is posing as a model for her boyfriend, the painter Little Billee, when she is overcome by a sudden headache - though the actress's rendition more closely resembles a hysterical fit. Called upon to help the girl, Svengali hypnotizes her. As Trilby sits in front of him, the man moves his hand, from his eyes to hers, with one or two fingers pointed; then, keeping his palms open, he waves both hands, repeatedly and alternately, in front of the girl's face. At this point she initially composes her body in a cataleptic state and then suddenly becomes animated, as if staring at a series of invisible images. (Figure 10.4) The waving gesture is repeated and reversed at the end of the sequence: after a violent backlash by Little Billee and the group of painters living with him, Svengali brings Trilby back to reality and does so by waving his hands in front of her face, twice, as if to dissolve an invisible curtain.

In this example, the gesture of Svengali's hands seems to first compose and then dissolve a sort of invisible screen right in front of Trilby's eyes: some kind of veil or curtain, capable of both isolating the subject from her social environment and of reflecting a series of images, projected directly-or so it appears - by the subject's mind. This last impression is further accentuated in the same sequence by the presence of two other surfaces that are similarly

3 In addition, see also Une scène d'hypnotisme I e II (Lumière, 1896), Mesmerist and Country Couple (Edison, 1899), 1904; Le Baquet De Mesmer (Méliès, 1904). For other references to film representing hypnotism in the 1910s, see Andriopoulos, pp. 92-127; and Gordon, p. 128 and pp. 141-166. 


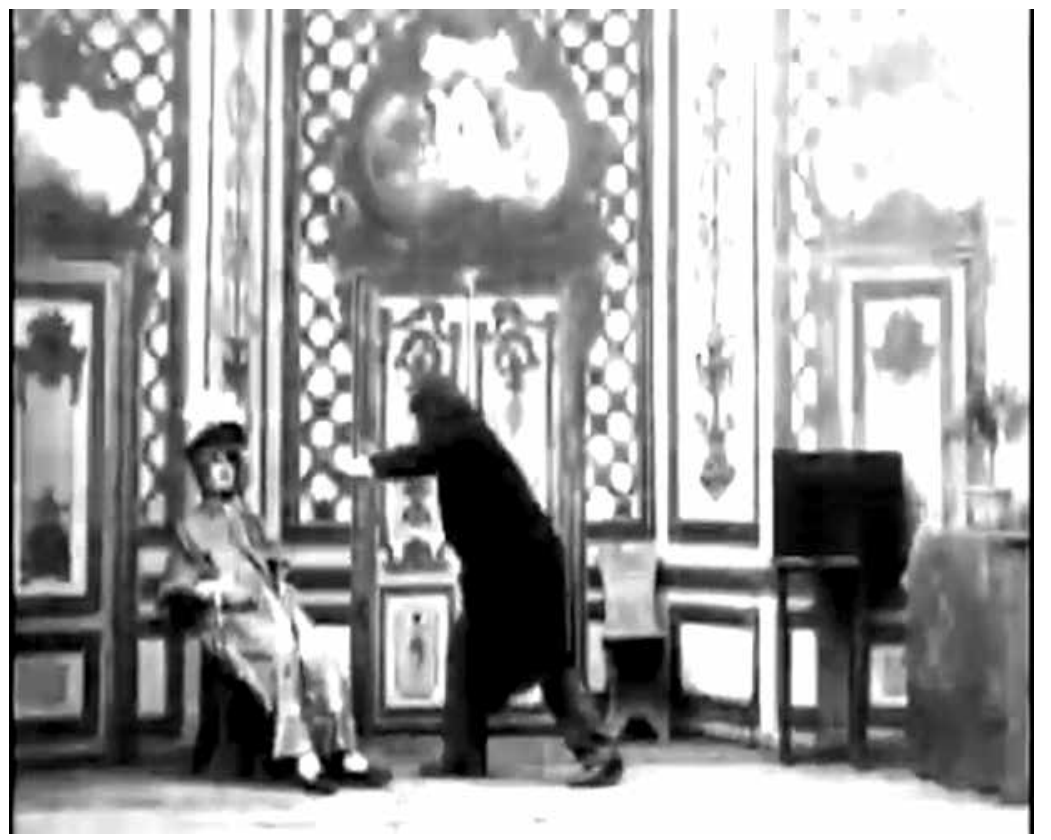

10.1: Alice Guy-Blaché (1873-1968), Frame enlargement from Chez le Magnétiseur, 1898.

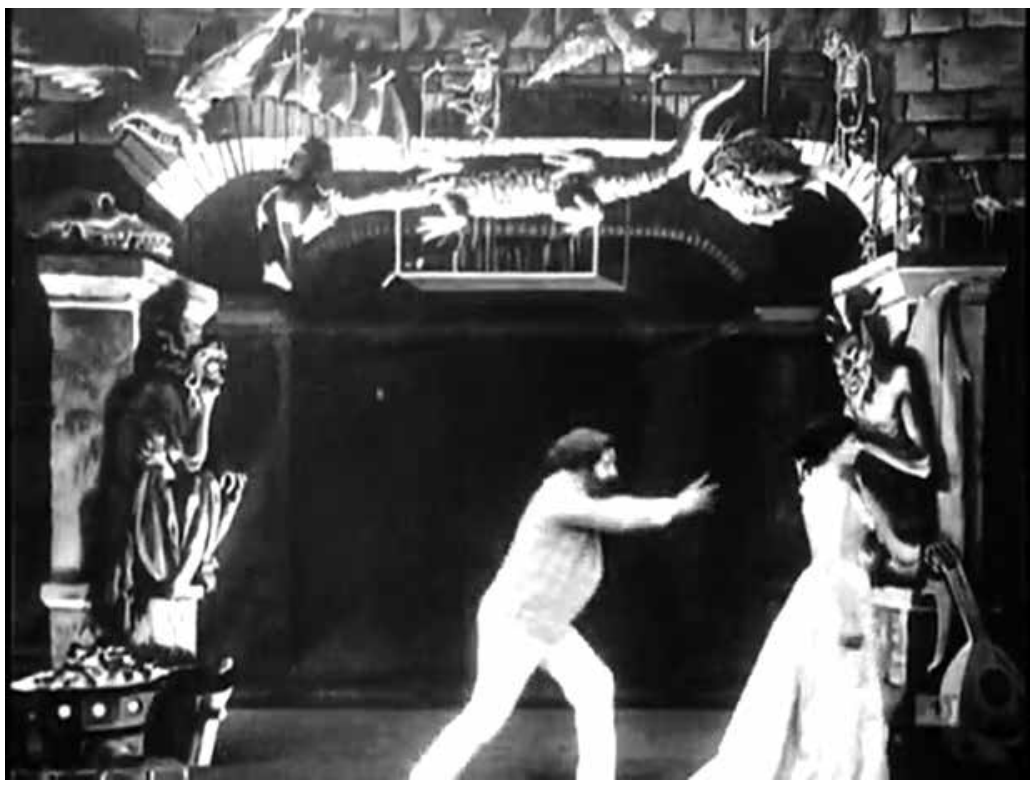

10.2: Georges Méliès (1861-1938), Frame enlargement from L'Antre des Esprits, 1901. 


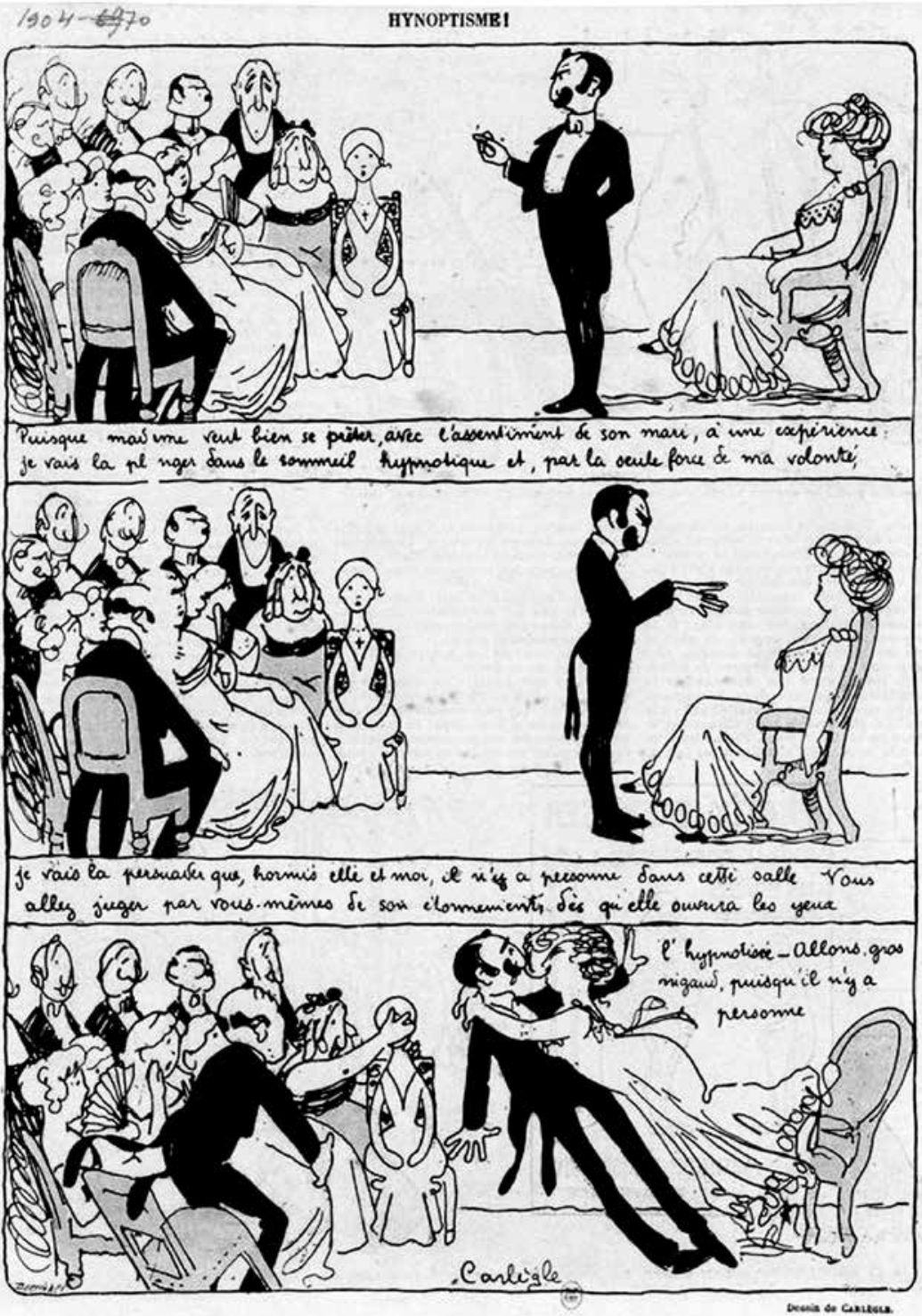

10.3: Charles-Émile Carlègle (1877-1937). Hypnotisme. 1904. BNF, Collection Jaquet, Dessinateurs et humoristes, Tome 1. 


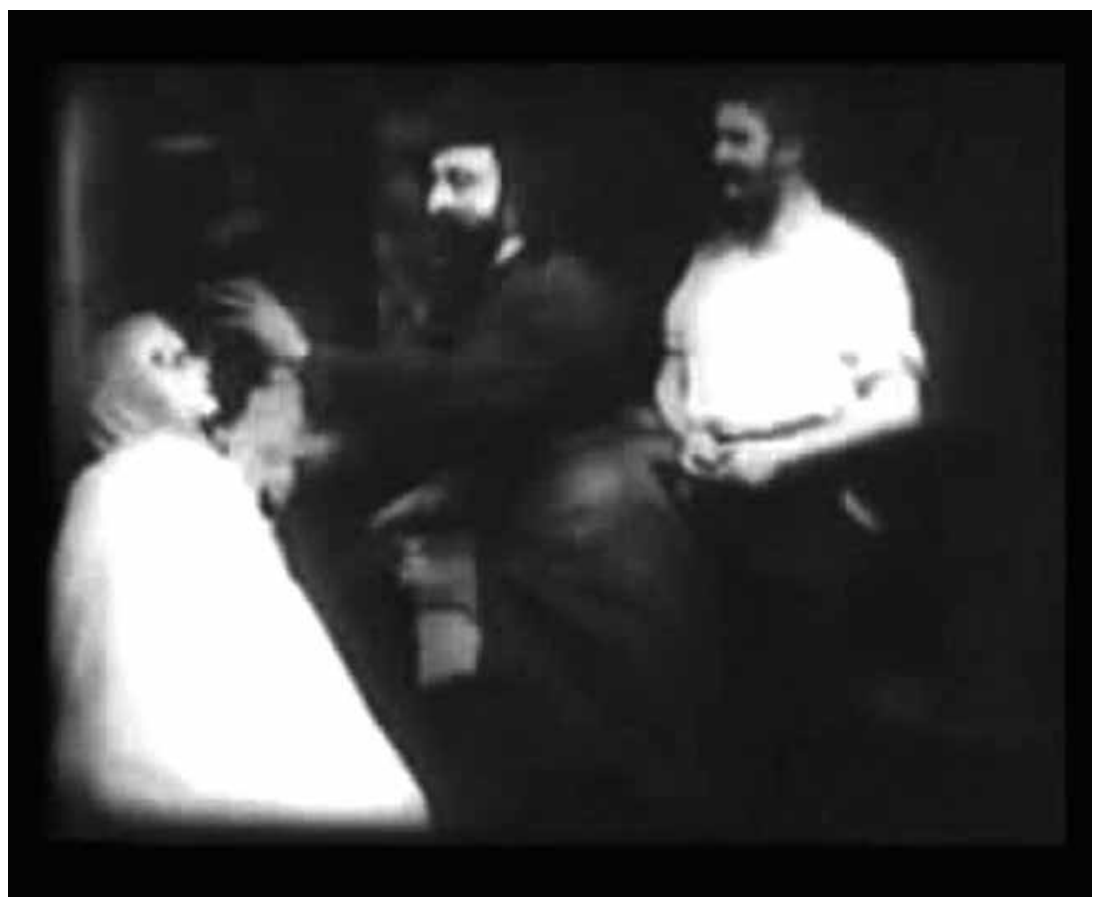

10.4: Maurice Tourneur (1876-1961), Frame enlargement from Trilby, 1915.

capable of supporting images: first, the shower curtain, behind which one of the painters' silhouettes appears just before the sequence of Trilby's hypnosis; second, the canvas on which Trilby's young lover is painting a portrait of her and which appears in the foreground during the first part of the sequence. ${ }^{4}$

A less obvious but equally interesting example can be found in 'Les yeux quifascinent' ('Hypnotic Eyes'), episode six of the popular French serial Les Vampires (Louis Feuillade, 1916). In this episode, the criminal Moreno hypnotizes his maid and then proceeds to kidnap Irma Vep (a femme fatale in the service of the Grand Vampire) in order to replace her with the hypnotized girl. With the purpose of orchestrating the switch, Moreno intoxicates Irma Vep with chloroform before releasing his hypnotized maid from her hiding place in a large trunk. As the girl stands before him, Moreno waves his open

4 Not surprisingly, the gesture of Svengali is also reminiscent of the film projector's shutter, since it alternates light and shadow on the woman's face. For the importance of the visual and pictorial aspects of Tourneur's film, see Askari, 2015. For a more general discussion, see Eugeni, 2014. 


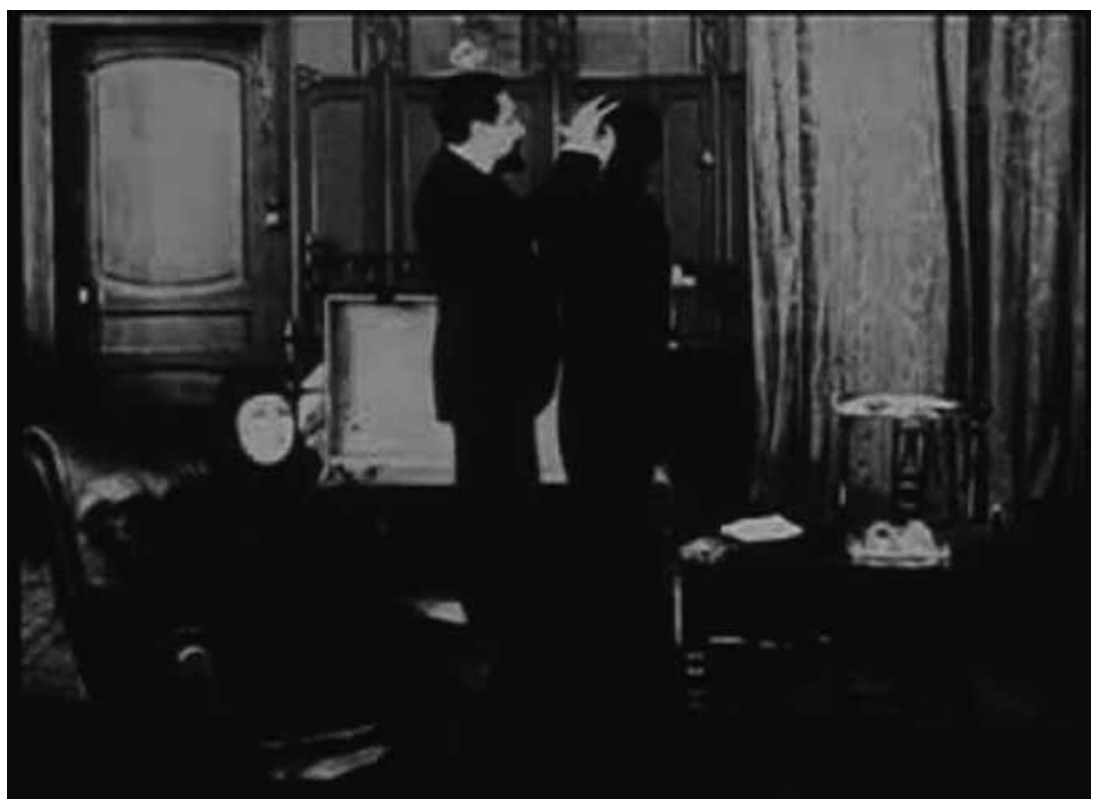

10.5: Louis Feuillade (1873-1925), Frame enlargement from Les Vampires, Episode 6: « LesYeux qui Fascinent ». 1916.

hand twice in front of her face, causing her to transition from a lethargic to a catatonic state: in short, she becomes a puppet, manipulated by Moreno's imperious gestures. 5 (Figure 10.5)

In this case, the gesture of circling one hand in front of the woman's eyes does not induce hypnosis but rather reactivates a state in which the (male) hypnotist exerts control over the (female) hypnotized subject. More exactly, the gesture has the effect of animating an inert body, turning it into a moving (albeit controlled) one. Nor should we neglect a series of not-too-implicit meta-cinematographic references embedded within this sequence. Two motifs are at work here: shadows, on the one hand (both the maid and Irma Vep cast masked silhouettes) and doubles, on the other hand (the mirrors, the two interchangeable women, etc.), both alluding in different ways to the nature of cinematic images. Within this network of references, the gesture of Moreno's hands evokes the twofold power of the cinematic situation: the capacity to turn still shadows into moving and living images (with the maid's body acting as a metaphor for the cinematic image), and the power to control, through the display of these images on the screen, the 'automated' 
viewer's body and its reactions (with the maid also acting as a metaphor of the viewer's body in front of the screen). In sum, the hypnotist appears as a grand imagier, able to activate, deactivate, reactivate, and regulate the movements and actions of both images and bodies.

Of Dr. Mabuse: The Gambler (Fritz Lang, 1922), Raymond Bellour has written, 'It is with [this double film] that a joint evaluation of the dispositives of cinema and of hypnosis seem to cover the range of their possibilities for the first time. ${ }^{6}$ What is most relevant, from this point of view, is that Lang explicitly overlaps theatrical and hypnotic settings: in fact, in the well-known sequence at the Philharmonic, Mabuse, disguised as the stage hypnotist Sandor Weltmann, causes a collective hallucination in the audience by showing a caravan of Bedouins descending from the stage down the aisles of the hall. Again, I suggest we focus our attention on Mabuse/Weltmann's gestures.7

Having delivered a brief introductory speech, Mabuse/Weltmann moves stage left (or, for viewers, to the right end of the frame) and brings his left hand to his face, with his palm turned outwards; then, with a flourish, he slowly lowers the same hand, still open, upon the audience. (Figure 10.6) Two details further amplify the impact of his gesticulation: first, Mabuse, in his disguise, pretends here to be deprived of his right hand; second, because of an 'imperfection' in the editing, his gesture as he lowers his open left hand is shown twice. During the hallucinatory caravan appearance that follows, Mabuse/Weltmann always keeps his hand open, first toward the audience, then toward the images of the moving caravan. (Figure 10.7) Eventually, the man lifts his hand again, slowly, before suddenly closing his palm and yanking back his arm, as if to tear apart an invisible veil: in the hall, the images abruptly disappear.

In this example, hypnosis works from within a theatrical situation but turns it into a cinematographic one. If the example from Les Vampires discussed above could be seen to signify a shift from photography towards moving images, here we can thus find a similar move from theatre to cinema. In this sense, the role of Mabuse/Weltmann's hand is crucial, since it symbolically replaces the two elements of the cinematic situation that are physically absent from the hall yet that are nonetheless necessary to operate the cinematic machine: the screen (his hand stretched out towards the audience) and the projector (his hand pointed toward the hallucinatory images of the moving caravan).

6 Bellour, p. 391.

7 According to Tom Gunning, Mabuse appears here as a 'grand enunciator'. Gunning focuses on the gaze of Mabuse, while my analysis emphasizes the role of his hand, and in general of his mimicry. Gunning, 2001, pp. 87-116. 


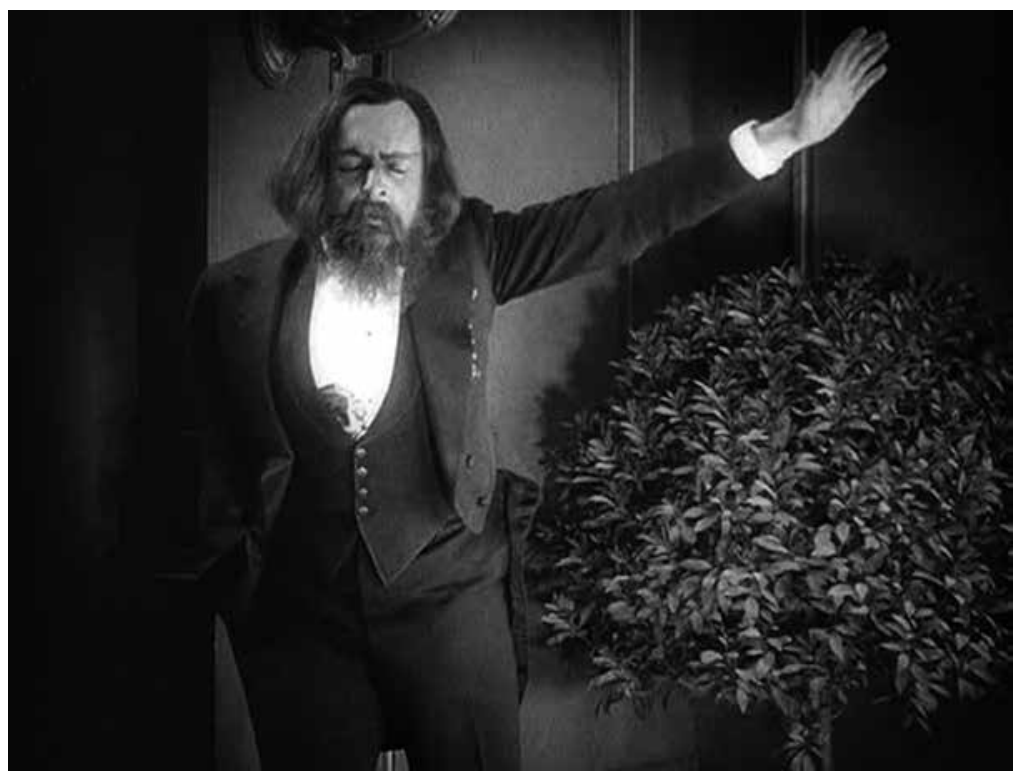

10.6: Fritz Lang (1890-1976), Frame enlargement from Dr. Mabuse, der Spieler. Zweiter Teil: INFERNO, Ein Spiel von Menschen unserer Zeit, 1922.

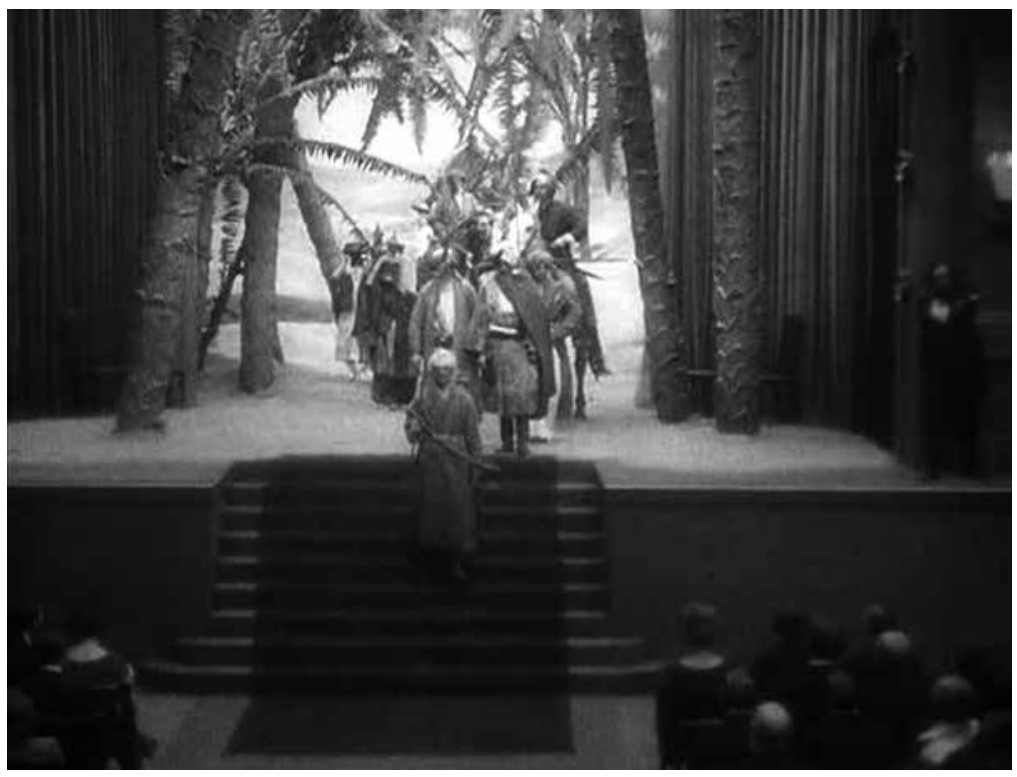

10.7: Fritz Lang (1890-1976), Frame enlargement from Dr. Mabuse, der Spieler. Zweiter Teil: INFERNO, Ein Spiel von Menschen unserer Zeit, 1922. 
Dr. Mabuse: The Gambler is not the only film of the Weimar period to combine openly cinematic and hypnotic settings. Another good example is Schatten. Eine nächtliche Halluzination (Warning Shadows, Arthur Robinson, 1923). In this movie, a mysterious figure infiltrates a mansion where a luxurious party is taking place. After turning the living room into a makeshift screening room, he first proceeds to tell a dramatic story using shadow puppets and then causes a collective hallucination in which both hosts and guests end up witnessing, and even actively participating in, that same story.

Here, two distinct dispositives are deployed in succession: first the shadow play and then the hypnotic hallucinations. Both, however, clearly allude to the cinema. A spatial overlap, in fact, connects the projection screen and the space in which the collective hallucination takes place. In this case, the trance-inducing gesture of waving an open hand is almost absent. It re-appears, however, in a brief moment towards the end of the sequence: as the latest images of the hallucinatory film-inside-the-film fade out, the hypnotist-projectionist appears alongside the shocked viewers, looks into the camera, and passes his hand in front of his eyes, as if to wipe clean his field of vision - a gesture immediately mimicked by the countess who is hosting the party. (Figure 10.8)

In conclusion, considering these meta-cinematic scenes of hypnosis, how, should we regard the transition from the throwing of fluid upon the subjects to the waving of a hand before their faces? In order to answer this question, we must consider this transformation against a wider background. In the same years as the movies we just analyzed were released, much of the emerging film criticism and cinema theory as well as a number of discourses produced by journalists, psychiatrists, and writers emphasized the 'structural affinity' between the film experience and the hypnotic trance. ${ }^{8}$ During the 1910 s, the metaphorical overlapping of cinema and hypnosis became a widespread topos. Some films took part directly in this tendency, and they can be seen, therefore, to use the representation of hypnosis both to mirror and to shape, in imaginary terms, the situation experienced by the film viewer.

Within this context, in fact, the act of launching magnetic energy does not disappear but is deeply transformed into the shining of the hypnotist's eye or into the twinkle of a brilliant object handled by him or her. In this way, a metaphorical relationship between the passage of magnetic power and the beam of the film projector is established: in this respect, we can speak of the (hypnotist's) hand-as-projector. At the same time, however, a radically new 


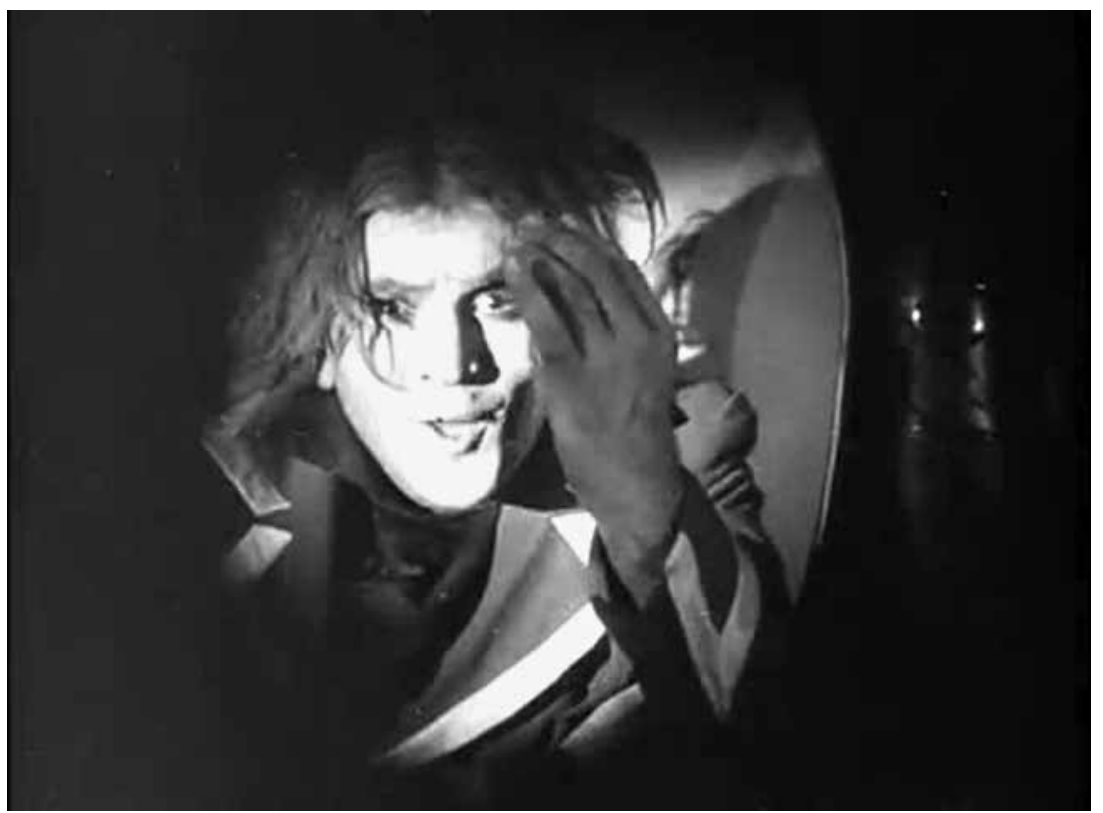

10.8: Arthur Robison (1883-1935), Frame enlargement from Schatten. Eine nächtliche Halluzination. 1923.

metaphor appears: the gesture of the hand passed in front of the hypnotized subject introduces a reference to the other essential component of the filmviewing situation, the screen. The hand-as-projector is thus undermined by the new metaphorical gesture of the hypnotist's hand-as-screen. Although the two metaphors coexist and compete, the latter tends to prevail. Different reasons account for such prevalence, partly linked to the centrality of the screen in the formulation of the filmic-hypnotic situation, which I will discuss below. For the moment, in light of our analysis, we can suggest that the new gesture of the hand-as-screen prevails because it enables a richer and more articulated system of metaphorical references. Indeed, at least three different specific functions of the screen emerge in connection to the gesture.

First, the hand-as-screen refers to the screen as an environmental component of the film-viewing situation: it is intended to build a situation of isolation and concentration of the subject's attention. Consequently, as a spatially situated device, it is apparently meant to induce a state of psychic and social separation of subjects from their own environment and their installation in a new, heterotopic scene-an intimate sphere with a private regime of perception and relationships (see, particularly, Trilby and Les Vampires). 
Second, the hand-as-screen represents the actual projection screen as an operational component of the film-viewing situation and refers to the hypnotist as the operator of the trance induction. It activates (in Trilby and Mabuse), re-activates (in Les Vampires), or de-activates (in Schatten) the hypnotic state. Moreover, from this perspective, the gesture expresses a further and deeper meaning of the cinematic situation, since the imaginary screen appears here as a means for 'handling' both moving images and the bodies of the viewers.

Finally, the imaginary screen drawn by the hypnotist's hand alludes to the actual screen as a documental component of the film-viewing situation: it is intended as a surface allowing the 'resurfacing' of subjective hallucinatory images and by this way their intersubjective observation. It is worth noting an ambiguity in this regard, since the surface evoked by the hand-as-screen gesture can function both as a 'catoptric' and a 'dioptric' surface ${ }^{9}$ — that is, as a private and intimate 'image machine' that passively receives and refracts moving images produced elsewhere and projected from a distance (Trilby, Les Vampires); and as a public and collective 'visual' or 'sight machine' that actively produces and externalizes moving images (Mabuse, Schatten). If in the first case a screen needs a (yet imaginary) projector (for instance, the subject's or the hypnotist's mind), in the second case the screen is the projector. At the same time (in documental terms), in the first case the film spectator cannot see the hallucinatory image experienced by the hypnotized character, while in the second case characters and spectators share the same visions.

\section{Obsessing images}

In this section I intend to further extend my observations and analyze the encounter between cinema and hypnosis from the point of view of an archaeology of the hypnotic setting. ${ }^{10}$ From this new perspective, cinema no longer appears as the object of a metaphorical transference from hypnosis but rather as an essential component of the history of 'modern' hypnosis.

9 On this point, I adopt and reinterpret some suggestions from Zielinski, 2013. Note that the screen as a dioptric surface incorporates some of the features attached to the projector's beam-as-blow of magnetic energy within the new and larger metaphorical framework of the hand-as-screen.

10 Here I refer to and expand what I previously argued in my book La relazione (Eugeni, 1993). On the history of hypnotism, see Crabtree, 1993; Ellenberger, 1970; Forrest, 2000; Gauld, 1992; Mayer, 2013; Monroe, 2008; Roussillon, 1992. 
As it is well known, hypnosis evolved from 'magnetism' or 'mesmerism' with Franz Anton Mesmer's para-healing practices at the end of the eighteenth century. However, the 'classic' magnetic setting took shape when the Marquis de Puysegur transformed the technique in 1784: its purpose was no longer to induce para-epileptic seizures in the patients but rather to immerse them in a state of artificial sleepwalking. From this point on, magnetism became, for almost all of the nineteenth century, a show of public intimacy: it implied a clearly defined division of roles between the couple immersed in the intense magnetic relationship and an audience carefully observing their movements and poses. Against this backdrop, two different and parallel narrative paths emerged. On the one hand, sleepwalkers could be entirely dependent on the operators for their perceptual ability, emotions, agency, memories, and so on. On the other, they could also reach the status of seers: they could guess the thoughts of the attendees, read a book even if blindfolded, penetrate with their sensibility their own bodies and those of others, even access other dimensions, and, afterward, bear testimony to what they had seen.

To sum up, the setting of the classical hypnotic setup is defined and made distinct by three orders of elements: from a topological point of view, the delimitation of the magnetic scene through a set of gestures explicitly designed to activate the sleepwalking state; from a relational point of view, the distinction between a magnetic pair (doctor/patient) and a collective audience; from an epistemological point of view, the sleepwalker's access to the invisible or unknown and the specific modalities of his or her revelations of this 'other scene' to the audience.

Two elements are especially relevant for our purposes. First, classical hypnosis does not entail the use of screens - except, perhaps, opaque surfaces limiting the view of the seer and challenging his or her ability. Indeed, the subject's gaze and body inhabit the invisible rather than just looking at something immaterial on a flat surface. Second, the waving of one's hand before the eyes of the patient is not contemplated as a technique to induce the magnetic state-except, perhaps, in the case of a heretic and anti-fluidic mesmerist such as the Abbé de Faria. ${ }^{11}$

11 The abbot José-Custodio de Faria (1756-1819) was an ambiguous figure of a priest coming from Goa, through Rome and Portugal, operating in Paris in the very first years of the nineteenth century. He anticipated the idea of 'suggestion', typical of the end of the century. Indeed, according to him, the state of trance is not due to an exchange of magnetic fluid; instead it depends on a state of suggestion that affects the sleepwalkers (the époptes, or seers, in Faria's terms); consequently, the gesture of the hand passed before their eyes is aimed to produce a state of exceptional concentration, plunging the époptes in their cataleptic state. 
The complex and dynamic equilibrium of the classical setting of magnetism is gradually revisited and deconstructed during the 'post-classical' period. At the end of the 1870 s, Jean Marie Charcot 'had the idea of artificially reproducing [hysterical] paralyses, and [...] for this purpose he made use of hysterical patients whom he put into a state of somnambulism by hypnotizing them'. ${ }^{12}$ With him, hypnosis became a tool to artificially activate, break down, assemble, and replicate the symptoms of hysteria. ${ }^{13}$ The hypnotic setup inaugurated by Charcot at the Salpêtrière hospital maintained the relational and topological features of the classical scene, but, crucially, it deconstructed the epistemic ones; more specifically, it deprived the sleepwalker of the role of seer. The hypnotized subject became 'la chose de l'expérimentateur', and his or her speaking body was transformed 'en véritable phonographe d'Edison'. ${ }^{4}$ Towards the end of the century, therefore, the clairvoyance of the seer as a defining trait was eliminated from the hypnosis scene and shifted towards the new experimental and theatrical scene of Spiritualism. ${ }^{15}$

The Nancy School, in its competition with Salpêtrière, was even more radical in deconstructing the classical scene of magnetism. Here, Hippolyte Bernheim (inaugurating his interventions in 1884) focused on the concept of suggestion, which he regarded as the influence exerted by a subject on another one by instilling 'ideodynamic' images without the need for specific and ritualized gestures. As a consequence, hypnosis was now merely considered a specific case of suggestion, one that involved the hypnotist as well as the hypnotized - and even the audience. In this way, the relational feature of the classical scene is critically undermined. On the other hand, hypnosis as suggestion is no longer limited to a specific setting but can potentially occur, in different forms, in all sorts of social contexts: patients do not need to be hysterical to be suggested, nor does one need to be a hypnotist in order to exert suggestion. In short, the topological feature of the classic magnetic scene is also radically deconstructed.

As a consequence of this progressive deconstruction, the setting of post-classical hypnosis became increasingly de-individuated and less strictly codified; hypnotic suggestions and resulting hallucinated visions expanded and spread widely across fin de siècle society: in the new 'discourse networks' of the twentieth century, see Kittler, 1997.

15 See Natale, 2016; Peters, 1999. 
performances of stage hypnotists, who no longer used trusted sleepwalkers but directly hypnotized members of the audience; in the resulting 'epidemics of hypnotism' that extended beyond performances and worried jurists, moralists, and scientists; in the very mechanics of crowds and societies analyzed by social psychologists; at the root of criminal phenomena investigated by legal and anthropological theorists; and even in the immersive and dreamlike states typical of the aesthetic experience. Once again, it is worth noting that these different and varied types of post-classical hypnosis neither make use of any kind of screens nor specifically use the hand passed before the eyes of the subject as a way of inducing suggestion.

We are therefore led back to the period we started from: the 1910s, the historical background of 'modern' hypnosis. I intend to advance three related hypotheses. First, if classical hypnosis was characterized by the progressive individuation of its settings, and if the post-classical period saw a de-individuation of them, modern hypnosis entails an opposite process of re-individuation. The resulting newly redefined setup, however, no longer requires a magnetic pair acting in front of an audience, but rather a hypnotist who acts on a group of subjects, thus turning them into an audience.

Second, the film-viewing situation represents the great cultural model for the new hypnotic setting. From this point of view, the metaphorical overlap of the cinematic situation and the modern hypnotic setup is symptomatic of a deeper phenomenon: cinema becomes the new hypnotic scene of modernity. As I said at the beginning of this section, cinema should be considered not simply a metaphor of hypnosis but rather an essential component of its cultural history.

My second hypothesis has an important corollary. Early cinema has often been described as a dispositive able to assemble, revitalize, and give better voice to those visionary practices that could not find a space in its coeval media. ${ }^{16}$ From the point of view I propose here, on the contrary, cinema appears to narrow down and to regulate the forms of artificial production, circulation, and consumption of the visible. If early cinema reflects a social anxiety related to the uncontrolled spread of images, it does so in order to discipline this circulation and thus reduce such anxieties.

Finally, my third hypothesis is that cinema can serve as a model for the modern setup of hypnosis thanks to the presence of the screen within the 
film-viewing situation. The screen-which, as we saw, was completely missing in both the classical and post-classical settings-becomes, in turn, the central site of reorganization for the modern setting of hypnosis. This dynamic can therefore explain the key role of the hand-as-screen metaphorical gesture and its predominance over the hand-as-projector metaphor within the meta-filmic representations of hypnosis I analyzed above.

To fully understand this key point, I refer back to the three functions of the hand-as-screen delineated at the end of the previous section and compare them to the three specific features that characterize the hypnotic setting of modernity.

First, the screen as an environmental component is a sheltering device that focuses the spectator's attention and retains it within a specific space; it protects the spectator's attention from the break-ins and interruptions of external reality; with its ignition and its extinction, a projection on a screen marks the beginning and the end of the film experience. Thus, the screen appears both as producer and synecdoche of a new topological definition of the hypnotic scene. ${ }^{17}$

Second, the screen as an operational component marks the presence of the hypnotizer within the setup. The screen takes the role of the hypnotist, while its size and location make him a dominant figure whose influence is aimed at the viewers so that each of them is involved in the suggestion and, at the same time, they are all transformed into a unitary social group. In this way, a new relational configuration is built within the hypnotic scene, one based on the model of the hypnotist enchanting a crowd. Even individual hypnosis becomes a different declination of that setting: as Freud argues, après coup in 1921, in this new modern magnetic scene, 'the hypnotic relation is [...] a group formation with two members [... so that] hypnosis has a good claim to being described as a group of two'. ${ }^{18}$

Finally, the screen as a documental component is the surface on which hypnotic, subjective hallucinations manifest themselves in an objective way and, at the same time, where objective stimuli appear to become subjective hallucinations. Spiritualism and clairvoyance can therefore be reintroduced within the epistemic dimension of the new hypnotic scene.

17 On hypnosis and cinema as 'technologies of attention', see Crary, 1999; Rogers, 2014. On the dialectical coexistence of 'protection' / 'concealment' on the one hand, and of 'showing' / 'monstration' on the other, see Avezzù, 2016.

18 Freud, 1949, pp. 78 and 100. 


\section{Actual screens, imaginary screens, dispositives}

We have, at this point, all the elements to interpret in full the phenomenon from which we started: the changes taking place between the 1910s and the 1920 in the iconography of the hypnotic induction in filmic representations; changes that consist, mainly, of the shift from the motif of the hypnotist's fingers pointed directly at the subject's body to a new gesture, one in which the hypnotizing hand is waved or circled in front of her eyes.

Three closely related events, I believe, explain this situation. The first is the association and merging of cinematic spectatorship and the modern hypnotic setting that takes place during this period. Second, many films further promote this association by the staging of situations of hypnosis in ways that are endowed with rich, articulate, and complex metaphorical references to the film's viewing situation. Finally, the cinematographic screen plays a key role in allowing and encouraging the identification of the hypnotic and the cinematographic: the screen is in fact a centralized operator of hypnosis acting on a crowd of viewers, and thus becomes the perfect model of the modern hypnotist. In light of these three elements, the transformation I have described in this essay can be explained as a shift of accent from the metaphor of the hypnotist's hand-as-projector to that of the hypnotist's hand-as-screen.

These conclusions lead me to focus the last section of this essay on the cinematic screen, in order to consider more carefully the radical transformations it underwent during this period. Film historians and media archaeologists have accurately documented a series of material innovations: the 1910s see a new attention to the architectural and technical aspects of the screen, with the transition from the vaudeville curtain and the nickelodeon gilded frame to the larger silver screens of picture palaces. ${ }^{19}$ Alongside these, I wish to emphasize another type of transformation, which concerns the symbolic and imaginary values of the film screen. Indeed, at a time when the film's viewing situation ends up coinciding with the hypnotic one, the screen becomes the key element of the induction and maintenance of the state of hypnosis. ${ }^{20}$

19 See Huhtamo, 2004; William, 2005.

20 From this point of view, in addition to what we have observed above on the basis of film analysis, we can consider the journalistic and critical interventions of the same period. These repeatedly describe the film-viewing situation as a hypnotic setting. Not by chance, many writers' focus shifts during those years from the projector's beam to the screen itself as the site and means of inducing a semi- or para-hypnotic trance. In 1918, Emile Vuillermoz can still link the hypnotic nature of film to the action of the projector's beam: 'La foule est attirée par le 
In order to fully grasp the metamorphosis that the screen undergoes at this moment, we must face these transformations jointly. Indeed, the mutual interaction of material and technological aspects on the one hand and symbolic and imaginary ones on the other marks a decisive turning point in the history of the film screen: from a factual component of the film-viewing situation, it becomes a dispositive. In fact, we can consider a dispositive as an assemblage of different components (topological, technological, operational, symbolic, and imaginary) linked by a network of reciprocal relations of regulation and determination; ${ }^{21}$ on this basis, what we witness during the 1910 is exactly the dynamic constitution of one such assemblage, pivoting around the movie screen.

Furthermore, this shift of the cinema screen from a technological appliance to a cultural and actual dispositive allows us to highlight another aspect. As Giorgio Agamben pointed out, a dispositive is always a tool for managing wider economic dynamics. ${ }^{22}$ In this case, the screen as a hypnoticcinematographic dispositive inaugurates the confluence and synergy of at least three economic systems: an economy of space and attention (the screen as a topological component), an economy of light and other such flows of energy (the screen as an operating component), and an economy of trust and belief (the screen as an epistemic component). Consequently, around the idea of the screen as a dispositive there begins to emerge - no longer

faisceau lumineux de la projection, comme un vol de moucherons dans le rayon d'un phare. Dès que la lanterne s'allume, les moucherons humains accourent et s'immobilisent. Cette fascination impérieuse qui affaiblit singulièrement le libre arbitre et le sens critique des spectateurs [...] plonge le sujet dans un état physique assez voisin de l'hypnose'. Vuillermoz, p. 224. However, just a few years later, we see a diverse group of writers describe cinema's hypnotic effect quite differently: Carlo Mierendorff ('In these catacombs [...] everyone presses forward, toward that mighty, flickering square eye that conjures, threatens, and mesmerizes.' Mierendorff, p. 427); Alfred Döblin ('[The little man, or the little woman] flocks to the movie theatres. [...] There, in the pitch-dark, low room, a square screen as tall as a man shimmers over a giant audience, over a mass that this white eye spellbinds with its vacant stare.' Döblin, pp. 1-3); and Jean Epstein ('I will never find the way to say how much I love American close-ups! Point blank. A head suddenly appears on screen and drama, now face to face, seems to address me personally and swells with an extraordinary intensity. I am hypnotized.' Epstein, pp. 235-236). All these writers decidedly emphasize the key role of the screen. Nevertheless, the topos of the light beam as a means of hypnotic induction never entirely disappears; see, for instance, about sixty years later, Roland Barthes: 'In that opaque cube, one light: the film, the screen? Yes, of course. But also (especially?), visible and unperceived, that dancing cone which pierces the darkness like a laser beam. [...] As in the old hypnotic experiments, we are fascinated — without seeing it head on — by this shining site, motionless and dancing.' Barthes, p. 347.

21 Casetti, pp. 80-110.

22 Agamben, pp. 1-24. In this book, following the current English translation of Foucault's works, the French term 'dispositif' has been translated as 'apparatus'. 


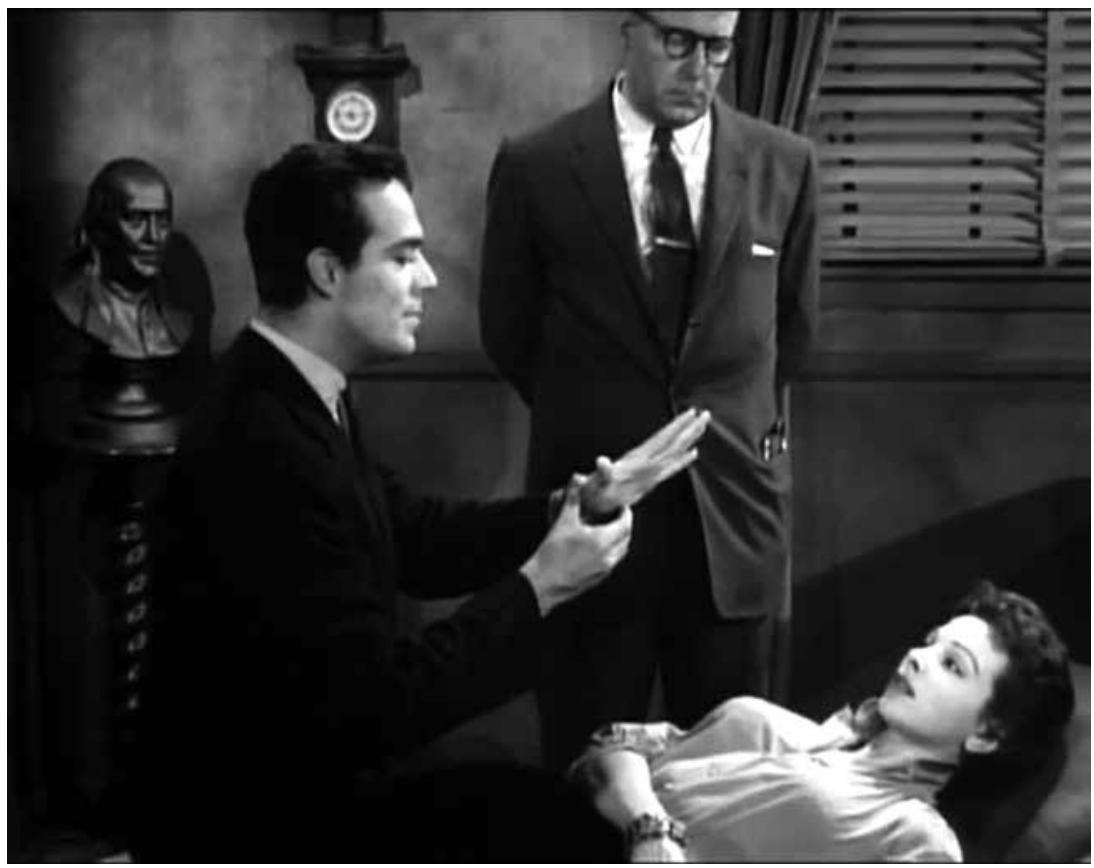

10.9: Roger Corman (b.1926), Frame enlargement from The Undead, 1957.

as a metaphorical overlapping but through a synecdochical shifting- the very idea of cinema as a dispositive.

Finally, a dispositive is also a form of cultural memory, one that extends its dynamic structure over time. It is no surprise, then, to see the metaphor of the hand-as-screen returning throughout the whole history of cinematic representations of hypnosis, at least until the 1980 . Accordingly, I conclude with an example that takes place thirty-four years after Schatten. In 1957, interest in hypnosis was very much alive in American cinema, following the success of such films as The Search for Bridey Murphy (Noel Langley, 1956), I've Lived Before (Richard Bartlett, 1956), and The Three Faces of Eve (Nunnally Johnson, 1957). Roger Corman exploited this trend by producing the film The Undead (1957); at the beginning of the movie, a physician (Richard Garland) induces deep hypnosis in a sex worker (Pamela Duncan) by placing his open hand before her eyes and intoning a long speech about hallucinatory images surfacing on his palm. (Figure 10.9)

Clearly, the distance in time has not weakened but has rather enriched the range of references and suggestions related to this gesture: the creation of a sphere of isolation and intimacy, the production of visionary experiences, the 
control and the power of the hypnotist over the subject. The hand-as-screen is still, after many years, an excessive surface, an uncanny site. Not only does this site negotiate the resurfacing of images, it also hosts the emergence of the Imaginary itself. ${ }^{23}$

\section{Works Cited}

Agamben, Giorgio. What is an Apparatus? and Other Essays. Translated by David Kishik and Stefan Pedatella. Palo Alto: Stanford University Press, 2009.

Albera, François and Maria Tortajada, eds. Cine-Dispositives: Essays in Epistemology Across Media. Amsterdam: Amsterdam University Press, 2015.

Alovisio, Silvio. L'occhio sensibile. Cinema e scienze della mente nell'italia del primo Novecento. Con un'antologia di testi d'epoca. Torino: Kaplan, 2013.

André, Emmanuelle. Le choc du sujet:De l'hystérie au cinéma XIX-XXI siècle. Rennes: Presses Universitaires de Rennes, 2011.

Andriopoulos, Stefan. Possessed:Hypnotic Crimes, Corporate Fiction, and the Invention of Cinema. Chicago: University of Chicago Press, 2008.

Askari, Kaveh. 'Trilby's Community of Sensation.' In Visual Delights II: Exhibitions and Receptions, edited by Vanessa Toulmine and Simon Popple, pp. 60-72. Eastleigh, UK: John Libbey Publishing, 2005.

Avezzù, Giorgio. 'Intersections between Showing and Concealment in the History of the Concept of Screen.' In Screens: From Materiality to Spectatorship - A Historical and Theoretical Reassessment, edited by Dominique Chateau and José Moure, pp. 29-41. Amsterdam: Amsterdam University Press, 2016.

Barthes, Roland. The Rustle of Language. Translated by Richard Howard. Berkeley: University of California Press, 1989 .

Bellour, Raymond. Le Corps du cinéma: Hypnoses, émotions, animalités. Paris: POL Traffic, 2009.

Berton, Mireille. Le corps nerveux des spectateurs: Cinéma et sciences du psychisme autour de 19oo. Lausanne: L'Age d'Homme, 2015.

Blassnigg, Martha, Gustav Deutsch, and Hanna Schimek. Light, Image, Imagination. Amsterdam: Amsterdam University Press, 2013.

Carroy, Jacqueline. Hypnose, suggestion et psychologie: Linvention des sujets. Paris: Presses Universitaires de France, 1991.

Casetti, Francesco. The Lumière Galaxy: Seven Key Words for the Cinema to Come. New York: Columbia University Press, 2015.

23 'Hypnosis has something positively uncanny [and] the characteristic of uncanniness suggests something old and familiar that has undergone repression.' Freud, 1949, p. 95. 
Chateau, Dominique and José Moure. Screens: From Materiality to Spectatorship - A Historical and Theoretical Reassessment. Amsterdam: Amsterdam University Press, 2016.

Crabtree, Adam. From Mesmerto Freud:Magnetic Sleep and the Roots of Psychological Healing. New Haven, CT: Yale University Press, 1993.

Crary, Jonathan. Suspensions of Perception:Attention, Spectacle and Modern Culture. Cambridge, MA: MIT Press, 1999.

Didi-Huberman, Georges. The Invention of Hysteria: Charcot and the Photographic Iconography of the Salpêtrière. Translated by Alisa Hartz. Cambridge, MA: MIT Press, 2003.

Döblin, Alfred. 'The Theatre of the Little People' (1909), translated by Lance W. Garmer. In German Essays on Film, edited by Richard W. McCormick and Alison Guenther-Pal, pp. 1-3. New York: Continuum, 2004.

Ellenberger, Henri F. The Discovery of the Unconscious: The History and Evolution of Dynamic Psychiatry. New York: Basic Books, 1970.

Epstein, Jean. 'Magnification' (1921), translated by Stuart Liebman. In French Film Theory and Criticism: A History/Anthology, Vol. 1: 1907-1929, edited by Richard Abel, pp. 235-236. Princeton: Princeton University Press, 1988.

Eugeni, Ruggero. La relazione di incanto: Studi su cinema e ipnosi. Milano: Vita e Pensiero, 2002.

- - . 'The Phantom of the Relationship, the Poverty of Cinema and the Excesses of Hypnosis.' In 'Dead Ends/Impasses', edited by Leonardo Quaresima, special issue, Cinema \& Cie, International Film Studies Journal 2 (spring 2003): 47-53.

_- . 'Voce, scena, suggestione in Trilby: La donna ipnotizzata dal romanzo di George du Maurier ai film di Maurice Tourneur e Archie Mayo (1894-1931).' In Scena madre. Donne personaggi e interpreti della realtà. Studi per Annamaria Cascetta, edited by Roberta Carpani, Laura Peja, and Laura Aimo, pp. 417-426. Milano: Vita e Pensiero, 2014.

Forrest, Derek. Hypnotism: A History. London: Penguin, 2000.

Freud, Sigmund. Group Psychology and the Analysis of the Ego. Translated by James Strachey. London: Hogarth Press, 1949.

- - . 'Charcot' (1893). In The Standard Edition of the Complete Psychological Works of Sigmund Freud, vol. 3, edited and translated by James Strachey, pp. 7-23. London: Hogarth Press, 1962.

Gauld, Alan. A History of Hypnotism. Cambridge, UK: Cambridge University Press, 1992.

Gordon, Rae Beth. Why the French Love Jerry Lewis: From Cabaret to Early Cinema. Palo Alto: Stanford University Press, 2001.

Gunning, Tom. The Films of Fritz Lang: Allegories of Vision and Modernity. London: BFI, 2001. 
Huhtamo, Erkki. 'Elements of Screenology: Toward an Archaeology of the Screen.' ICONICS: International Studies of Modern Image, Tokyo, vol. 7 (2004): 31-82.

_- . 'Messages on the Wall-An Archaeology of Public Media Displays.' In The Urban Screen Reader, edited by Scott McQuire, Meredith Martin, and Sabine Niederer, pp. 15-28. Amsterdam: Institute of Network Cultures, 2009.

- _ . 'Screen Tests: Why Do We Need an Archaeology of the Screen?' Cinema Journal 51.2, (2012): 144-148.

Killen, Andreas. 'The Scene of the Crime: Psychiatric Discourses on the Film Audience in Early Twentieth Century Germany.' In Film 19oo: Technology, Perception, Culture, edited by Annemone Ligensa and Klaus Kreimeier, pp. 153-172. New Barnet: John Libbey, 2015.

Kittler, Friedrich. 'Dracula's Legacy.' In Literature, Media, Information Systems: Essays, edited by John Johnston, pp. 50-84. New York: Routledge, 1997.

Manovich, Lev. The Language of New Media. Cambridge, MA: MIT Press, 2001.

Mayer, Andreas. Sites of the Unconscious: Hypnosis and the Emergence of the Psychoanalytic Setting. Chicago: University of Chicago Press, 2013.

Mierendorff, Carlo. 'If I Only Had the Cinema!' (1920), translated by Jeffrey Timon. In The Promise of Cinema: German Film Theory 1907-1933, edited by Anton Kaes, Nicholas Baer, and Michael Cowan, pp. 426-432. Oakland, CA: University of California Press, 2016.

Mitchell, W.J.T. 'Screening nature (and the nature of the screen).' New Review of Film and Television Studies 13.3 (2015): 231-246.

Monroe, John Warne. Laboratories of Faith: Mesmerism, Spiritism and Occultism in Modern France. Ithaca: Cornell University Press, 2008.

Musser, Charles. 'Toward a History of Screen Practice.' Quarterly Review of Film Studies 9.1 (1984): 59-69.

- - The Emergence of Cinema: The American Screen to 1907. London and New York: Simon \& Schuster, 1990.

Natale, Simone. Supernatural Entertainments: Victorian Spiritualism and the Rise of Modern Media Culture. University Park, PA: Pennsylvania State University Press, 2016.

Peters, John Durham. Speaking into the Air: A History of the Idea of Communication. Chicago: University of Chicago Press, 1999.

Richer, Paul and Gilles de la Tourette. 'Hypnotisme', in Dictionnaire Encyclopédique des Sciences Médicales, edited by Amédée Dechambre and Léon Lereboullet, quatrième série, Tome XV, pp. 67-132. Paris: Masson - Asselin et Houzeau, 1889.

Rogers, Kenneth. The Attention Complex: Media, Archeology, Method. New York: Palgrave MacMillan, 2014.

Ronetti, Alessandra. 'Les pratiques de suggestion dans 'Le peintre néo-impressioniste' (1910) d'Émile Cohl.' In Cinema, sogno e allucinazione dale origini agli anni 
Venti, edited by Silvio Alovisio and Mireille Berton, Special Issue of Immagine. Note di storia del cinema, n. 18, 2018, pp. 116.

Roussillon, René. Du baquet de Mesmer au “baquet” de S. Freud. Une archéologie du cadre et de la pratique. Paris: Presses Universitaires de France, 1992.

Schweinitz, Jörg. 'Immersion as Hypnosis: The Evolution of a Theoretical and Cinematic Stereotype in Silent Cinema.' In In The Very Beginning, At The Very End: On the History of Film Theories, edited by Leonardo Quaresima and Valentina Re, pp. 39-44. Udine: Forum, 2010.

Väliaho, Pasi. Mapping the Moving Image: Gesture, Thought and Cinema Circa 1900. Amsterdam: Amsterdam University Press, 2010.

Vuillermoz, Émile. 'Routine' (1918). In Le temps du cinéma: Émile Vuillermoz père de la critique cinématographique, edited by Pascal Manuel Heu, pp. 224-226. Paris: L'Harmattan, 2003.

Weingart, Brigitte. 'Contact at a Distance: The Topology of Fascination.' In Rethinking Emotion: Interiority and Exteriority in Premodern, Modern, and Contemporary Thought, edited by Rüdiger Campe and Julia Weber, pp. 72-10o. Berlin and Boston, De Gruyter, 2014.

William, Paul. 'Screens.' In Encyclopedia of Early Cinema, edited by Richard Abel, pp. 830-834. London and New York: Routledge, 2005.

Zielinski, Siegfried. 'Designing and Revealing: Some Aspects of a Genealogy of Projection.' In Light, Image, Imagination, edited by Martha Blassnigg, Gustav Deutsch, and Hanna Schimek, pp. 151-179. Amsterdam: Amsterdam University Press, 2013.

\section{About the Author}

Ruggero Eugeni is professor of media semiotics at Università Cattolica del Sacro Cuore in Milan. His interests are focused on the living media experience as defined both in historical-sociological terms and from a phenomenologicalneurocognitive perspective. On this basis, he is currently developing historical and theoretical research on filmic representations of hypnotism as metaphors for the cinematic dispositive and its experiential, cultural, and political implications. His leading works are 'Film, sapere, società. Per un'analisi sociosemiotica del testo cinematografico' [Film, Culture, Society. For a Sociosemiotic Analysis of the Film] (Milano, 1999), 'La relazione d'incanto. Studi su cinema e ipnosi' [The Enchanted Relationship. Studies on Film and Hypnotism] (Milano, 2002). His most recent monographic work is 'Semiotica dei media. Le forme dell'esperienza' [Media semiotics. Forms of Experience] (Rome, 2010).

Several of Eugeni's articles, papers, and preprints in English are available at http://ruggeroeugeni.com. 
